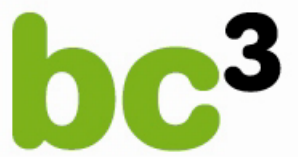

BASQUE CENTRE

FOR CLIMATE CHANGE

Klima Aldaketa Ikergai

\title{
Impacts of Climate Change on European Critical Infrastructures: The Case of the Power Sector
}

\author{
Dirk Rübbelke and Stefan Vögele
}

July 2010

BC3 WORKING PAPER SERIES 
The Basque Centre for Climate Change (BC3) is a Research Centre based in the Basque Country, which aims at contributing to long-term research on the causes and consequences of Climate Change in order to foster the creation of knowledge in this multidisciplinary science.

The BC3 promotes a highly-qualified team of researchers with the primary objective of achieving excellence in research, training and dissemination. The Scientific Plan of BC3 is led by the Scientific Director, Prof. Anil Markandya.

The core research avenues are:

- $\quad$ Adaptation to and the impacts of climate change

- $\quad$ Measures to mitigate the amount of climate change experienced

- $\quad$ International Dimensions of Climate Policy

- $\quad$ Developing and supporting research that informs climate policy in the Basque Country

See www.bc3research.org for further details.

The BC3 Working Paper Series is available on the internet at http://www.bc3research.org/working_papers/view.html

Enquiries (Regarding the BC3 Working Paper Series):

Roger Fouquet

Email: roger.fouquet@bc3research.org

The opinions expressed in this working paper do not necessarily reflect the position of Basque Centre for Climate Change (BC3) as a whole.

Note: If printed, please remember to print on both sides. Also, perhaps try two pages on one side. 


\title{
Impacts of Climate Change on European Critical Infrastructures: The Case of the Power Sector
}

\author{
Dirk Rübbelke*,** and Stefan Vögele***
}

Anthropogenic emissions of greenhouse gases cause climate change and this change in turn induces various direct impacts, e.g., changes in regional weather patterns. The frequency of heat waves and droughts in Europe is likely to rise. Yet, beyond these immediate effects of climate change, there are more indirect effects: Droughts may cause water scarcity and a lack in water supply which in turn would affect further sectors and critical infrastructures. An arising lack in water supply for cooling purposes, for example, will negatively affect the electricity generation in power plants.

In this paper we analyse such interplays between climate-change affected sectors. We investigate whether and to which extent power generation and supply in Europe is threatened by climate change because of the higher risk of water supply shortages due to more frequent drought and heat-wave incidences. Our proposed approach cannot only be applied to analyse the climate change effects on individual power plant sites or the overall economy but also on electricity exchanges between countries.

Keywords: $\quad$ adaptation, climate change, critical infrastructures, electricity trading, energy security, nuclear power plants, vulnerability

JEL classifications: Q54, Q41, H54, Q56

Cite as: Rübbelke, D. and Vögele, S. (2010), Impacts of Climate Change on European Critical Infrastructures: The Case of the Power Sector. BC3 Working Paper Series 2010-08. Basque Centre for Climate Change (BC3). Bilbao, Spain.

\footnotetext{
* Basque Centre for Climate Change (BC3), Gran Via, 35-2, 48009, Bilbao, Spain, email: dirk.ruebbelke@bc3research.org

** IKERBASQUE, Basque Foundation for Science, 48011, Bilbao, Spain

*** Forschungszentrum Jülich GmbH, Institute of Energy Research - Systems Analysis and Technology Evaluation (IEFSTE), 52425 Jülich, Germany, email: $\underline{\text { s.voegele@fz-juelich.de }}$
}

Acknowledgements: We thank Bettina Damm and Kristin Linnerud for helpful comments. The work devoted to this paper was partly funded under the CELECT project sponsored by the Research Council of Norway. 


\section{Introduction: Climate Change, Energy Security and Critical Infrastructures}

As Bohi and Toman (1996: 1) point out, “[e]nergy security refers to the loss of economic welfare that may occur as a result of a change in the price or availability of energy.” In general, the change in availability of energy influences the price of energy via market interaction (and vice versa), i.e. price and availability changes are interrelated. Yet, in many countries gas prices are indexed to the oil price, such that the gas price in these countries does not properly reflect potential shortages in gas supply. In the EU27, about $25 \%$ of total primary energy supply is covered by gas (EC 2008c: 12). Furthermore, on the oil market the OPEC cartel has market power. Aspects like the latter are more explicitly addressed in the concept of energy security conveyed by the IEA (2007: 12) which states that energy insecurity "stems from the welfare impact of either the physical unavailability of energy, or prices that are not competitive or overly volatile”, i.e., market power negatively affects energy security. ${ }^{1}$

Non-competitive prices are also a major concern of the EU, and one of the three main objectives of Europe's energy policy as outlined in the European Commission Green Paper (EC 2006a) is to improve the competitiveness of the European internal energy markets; the other two objectives are sustainability and security of supply. Since competitive prices contribute to energy security, it is apparent that the EU's individual energy policy objectives are closely related. In order to support supply security as well as competitiveness, a strong focus of the EU is put on investments in infrastructure in the shape of pipelines and grid interconnections (see EC 2008a).

In recent years a major concern in the EU was also the critical infrastructure protection (CIP) against terrorist attacks and other security related risks. In 2004, the EC adopted a Communication, i.e., a prelegislative proposal, with the title "Critical Infrastructure Protection in the Fight against Terrorism” (EC 2004) and, thereafter, in 2005, the Commission adopted a Green Paper (EC 2005) on a European Programme for Critical Infrastructure Protection (EPCIP). In the Green Paper, the need to help reducing vulnerabilities concerning critical infrastructures was acknowledged. The threats are seen in terrorism, natural disasters and accidents; the risk of any disruptions or manipulations of critical infrastructures should be minimised. Consequently, while the initial focus of the emerging European CIP policy was on terrorism as a threat for disruptions, the policy evolved into an all-hazards approach. In December 2006, the European Commission adopted a Communication (EC 2006b) which describes the overall framework for EU-level CIP activities.

\footnotetext{
${ }^{1}$ For a recent discussion of different concepts of and indicators for energy security, see Löschel, Moslener and Rübbelke (2010).
} 
The EPCIP consists of three main parts: 1) the Council Directive (EC 2008b) on the identification and designation of European CIs and the assessment of the need to improve their protection, 2) a financial programme, and 3) the Critical Infrastructure Warning Information Network (CIWIN). "While the Directive constitutes the core of the programme, the other two components are foremost measures designed to facilitate the implementation of the Directive” (Lindström 2009: 38).

The Green Paper (EC 2005) on the EPCIP adopts the principle of subsidiarity such that the EU would only be responsible for the CIP of those infrastructures whose disruptions would cause cross-border effects. Member States have to conduct CIP of those infrastructures whose disruptions would mainly affect the state itself, but their CIP is to be executed under a common EPCIP framework. Yet, the borderline between EU-wide critical infrastructures (CIs) and national CIs is a bit blurred (see also Pursiainen 2009: 724-725). The European Commission considers CIs to be European CIs, if they or disruptions of them significantly affect at least two EU member countries, while some critics suggested regarding only those CIs to be European CIs which involve three or more EU member states. In Council Directive (EC 2008b) on the identification and designation of European CIs and the assessment of the need to improve their protection, the European Council identifies energy and transport sectors as European critical infrastructures. Yet, the Directive also states that a step-by-step approach to identify and designate ECIs is pursued and that energy and transport sectors are those chosen in the first step. Other candidate sectors are 1) information, communication technologies, 2) water, 3) food, 4) health, 5) financial, 6) public and legal order and safety, 7) civil administration, 8) chemical and nuclear industry, and 9) space and research (see Annex 2 of EC 2005).

The relevant sectors can be split into subsectors and in this paper the energy subsector 'electricity subsector which includes infrastructures and facilities for generation and transmission of electricity in respect of supply electricity' (see Annex I of EC 2008b) is of main relevance while in the water subsector we are mainly interested in water supply issues. More specifically, we are interested in the links between these two subsectors despite the fact that the common EPCIP framework which - according to the Green Paper (EC 2005) - has to define competences and responsibilities of involved agents, envisages to settle CIP principles on a sector-by-sector basis. On the one hand, as Fritzon et al. (2007: 32) stress concerning this sector-by-sector approach: "Such a strategy allows for CIP to be tailored to different CI needs and varying legal competences for CIP across the policy spectrum.” Yet, on the other hand, the fragmentation of regulations must not go so far that spillovers and synergies between different sectors become disregarded and will not be exploited. "Assessing the impact of systemic interactions is one of the most important but least understood aspects of modern risk assessment” (IRGC 2009: 25). There are many examples of close relationships and interdependencies between different CIs. As Watts (2003: 559-560) 
explains, power grids might be affected by communication system disruptions (e.g., caused by terrorist attacks). Little (2002: 111) gives the example of failures in the communication system affecting the health sector. Svendsen and Wolthusen (2007: 44) refer to interactions between electric power grid and the telecommunications sector. De Bruijne and van Eeten (2007: 19) even stress that CIs "are becoming more dependent on each other's 'always on' availability” and as a consequence these infrastructures have “become increasingly vulnerable to large-scale, cascading disruptions across sectoral boundaries”. Or as

Kröger (2008: 1781) puts it: "recent decades have witnessed on the one hand a development towards a highly integrated system of interdependent systems, and on the other hand an increased social vulnerability in the face of loss of continuous operation”. He stresses that additional hazards and threats to CIs have also arisen.

The main threat we regard in our analysis is climate change causing a rise in the frequency and intensity of heat waves and droughts in Europe. These heat waves and droughts will negatively affect water supply and - indirectly - power generation. It is this connection between water supply and power generation which is in the focus of our analysis. By investigating the consequences of climate-change induced shortage of water supply (droughts), we follow the advice given by the OECD (2003: 50): “Attention has to be less focused on the occurrence and direct consequences of a hazard, and be more geared toward indirect cause-effect relationships, diffusion, and long-term effects.” While climate change is the initial effect induced by anthropogenic emissions of greenhouse gases, droughts are a successive indirect consequence which in turn generates another sequence of problems (disruptions in the generation of power).

\section{Supply Disruptions in the Energy Sector}

It seems that on a global scale natural-disaster impacts on CIs might be of minor relevance if we take a look at the global oil market. Only five major disruptions can be observed on the oil market since the early 1990s: Hurricane Katrina (with a gross peak supply loss of 1.5 mb/d) in 2005, the war in Iraq (gross peak supply loss of $2.3 \mathrm{mb} / \mathrm{d}$ ) in 2003, Venezuelan strike (gross peak supply loss of $2.6 \mathrm{mb} / \mathrm{d}$ ) in 2002/03, the Iraqi oil export suspension (gross peak supply loss of $2.1 \mathrm{mb} / \mathrm{d}$ ) in 2001 and the Gulf Crisis (gross peak supply loss of $4.3 \mathrm{mb} / \mathrm{d}$ ) in 1990/91 (see IEA 2007: 37). Hence, only one of the five major disruptions has been due to natural disasters or extreme weather events affecting the energy (oil supply) infrastructure. However, in the course of an ongoing climate change, the severity of such incidences and their effects on energy supply is likely to rise. 
On a geographically more limited scale, disruptions of energy supply induced by extreme weather events have been observed more frequently in the recent past. An obvious connection between weather extremes and energy supply is found in the hydropower sector. Hydroelectric power is the major source of electricity for 26 countries from the Sahel to southern Africa and the secondary source for further 13 countries (Showers 2002: 639). Due to droughts, several areas in these countries from a wide range of climates were negatively affected by power shortages in the 1980s and 1990s. Yet, water shortage, which is a threat that is probable to become more important in the course of climate change in many world regions, also negatively affects the power generation in fossil fuel and nuclear power plants. Such plants require water especially for cooling processes (Koch and Vögele 2009). As Förster and Lilliestam (2010) show, power generation could be severely constrained by typical climate impacts such as increasing river temperatures and decreasing stream flow.

Consequently, water shortages do not only threaten electricity generation in developing countries, e.g., those located in Africa, but also the power generation in industrialized countries, e.g., those located in Europe or North America. According to the IPCC (2008a), the frequency of periods characterized by water shortages and by high water temperatures will increase in Europe and other parts of the world in future. Such a period has been experienced in Europe, e.g., during the summer of the year 2003, and it constrained the functioning of several power plants, e.g., in Germany (Zebisch et al. 2005: 51). About 43 \% of the EU's water demand is used as cooling water by power authorities (EUREAU 2009: 21).

Consequently, climate change will affect the European CI 'water supply' infrastructure and simultaneously - due to the deficit of water supply - the European CI 'electricity generation' infrastructure. In the European Union, 40 of the 110 existing river basins are international (EC 2007: 20) and hence these 40 basins meet the European CI criterion to concern more than one country. Due to the European transnational grids and the transnational transfer of power, a disruption in the power generation in one country may also affect other countries, i.e. more than one country is affected by, e.g., a shut-down of a power plant.

As the EC (2007: 9) stresses "it is complex to establish European common indicators to describe droughts”. If prolonged drought occurs, a prioritisation of main uses should be established and for this objective, the EC (2007: 17) suggests employing impact indicators and among these proposed indicators are such reflecting impacts on socio-economic uses of water related to power production. As a means to deal with or prevent future water scarcity, the European Commission, e.g., intends to assess the need to further regulate the standards of water using equipment and water performance in different sectors (EC 2009a: 11). As Pulido-Velazquez et al. (2008: 52) point out: "The feasibility of water management strategies depends not only on the physic factors of the system, but also on their legal, institutional, 
environmental, and economic implications and constraints.” It is also suggested that adaptation measures related to water scarcity and droughts should be discussed in a transboundary and interdisciplinary context (EC 2009b: 100). The electricity sector itself also has options to adapt to climate change, but given the long lifetime of infrastructures and the magnitude of investments in the electricity sector, these adaptation options should be included already in today’s planning and strategies (BMU 2007: 2-3).

\section{Impacts of Climate Change on Nuclear Power Plants and Electricity Supply in Europe}

In the summer of 2003, more than 30 nuclear power plant units in Europe had to reduce their production because of limitations in the possibilities to discharge cooling water (IAEA 2004). Some nuclear power plants got exemptions from legal requirements to be able to continue their operating activities. Currently nuclear power has a share of 28\% in the electricity supply of the EU (Eurostat 2010). So disruptions in the use of the nuclear power plants may have significant impacts on the electricity supply system. In our analysis we will focus on this important subsector of energy generation.

Based on expected changes in climate, we will assess the impacts of climate change on the electricity system taking into account country-specific shares of nuclear power in the electricity system and the exchanges of electricity within the countries. Fig. 1 gives an overview of the distribution of nuclear power plants in Europe.

Nuclear power plants which had cooling problems in the past are highlighted. Most of the nuclear power plants in Europe are located in France. However, Germany, Great Britain and Spain also have a large number of nuclear power plants. The nuclear power plants with cooling problems in summer are mainly located in the south of Europe and onshore near big rivers.

Despite the exemptions from legal requirements for some nuclear power plants, the whole electricity exchange system was affected by the limitations in the production possibilities of the power plants: As a

result of the cooling problems of the nuclear power plants in 2003, France as the biggest electricity exporter had to import electricity from Great Britain to be able to supply enough electricity to Italy and other countries (UCTE 2004). The situation in 2003 shows that a heat wave in Europe can have a negative effect on the electricity supply system. Taking climate change into account, the question arises, if the situation of 2003 will become the norm or will still remain a more or less unique situation. 
Fig. 1: Nuclear power plants in Europe

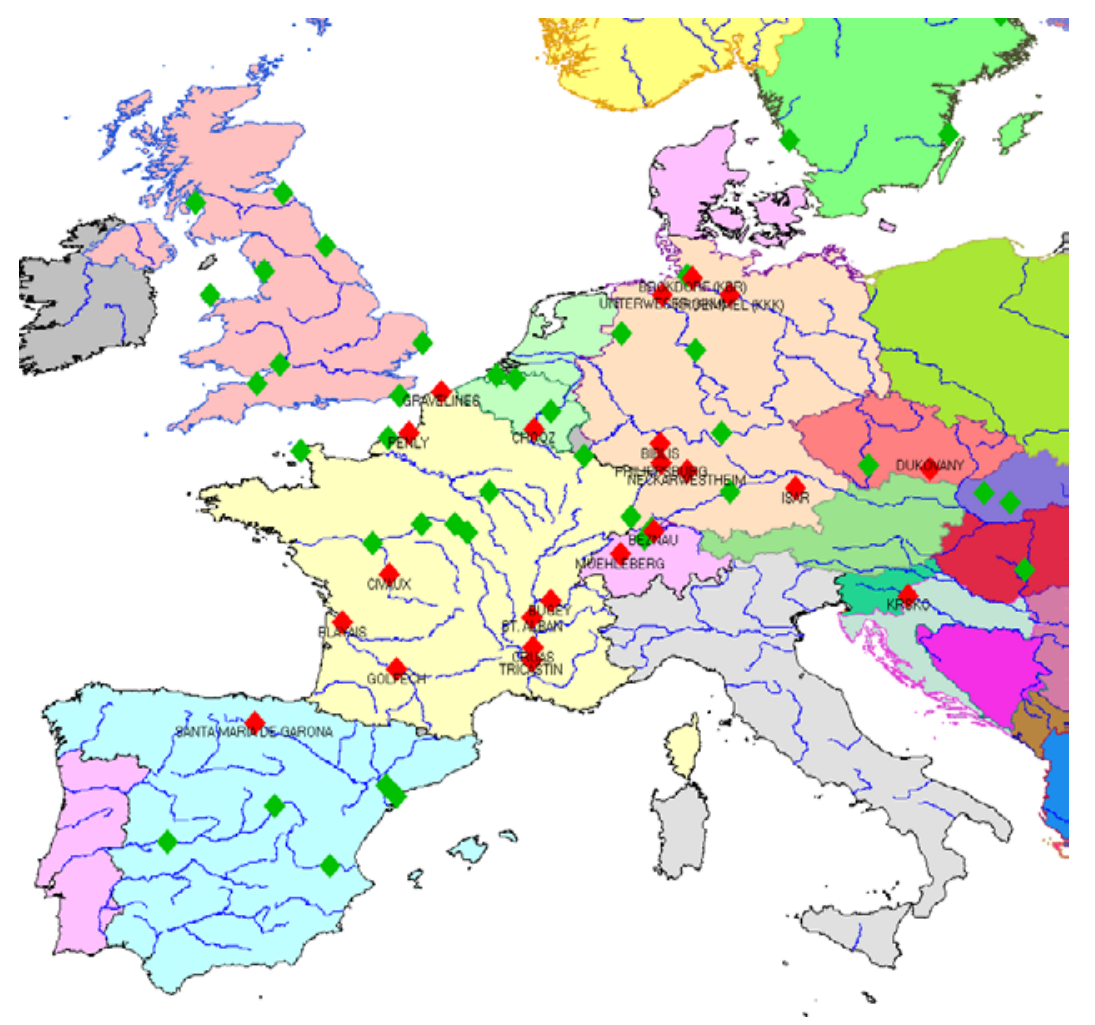

Remarks: Red: Nuclear power plants with cooling problems in recent years.

In the following, we will present an approach which allows us to analyse the impacts of climate change on the electricity supply system in Europe. The possible effects of climate change on power plants and other water users have been analysed in several papers (see, e.g., DOE/NETL 2007; EPRI 1995; Förster and Lilliestam 2010; Hurd and Harrod 2001; Koch and Vögele 2009; Müller, Greis and Rothstein 2007). In contrast to these studies, we want to present an approach that cannot only be applied to analyse the effect on individual power plant sites or the overall economy but also on electricity exchanges. Using the example of nuclear power plants in Europe, we will use this approach to point out possible impacts of changes in air and water temperatures on the European electricity exchange structure.

\section{III.1 Description of the Theoretical Approach}

To be able to assess the impacts of changes in humidity, air and water temperatures as well as in the availability of freshwater on production processes in thermal power plants it is necessary to analyse the freshwater demand of the power station that is needed to run the station without cooling constraints. The demand for freshwater of a thermal power plant can be calculated by 
$Q^{F}=\frac{K W \cdot h \cdot 3.6 \cdot \frac{1-\eta_{\text {total }}}{\eta_{\text {elec }}} \cdot(1-\alpha) \cdot(1-\beta) \cdot \omega}{\vartheta \cdot c \cdot A S} \cdot E Z$

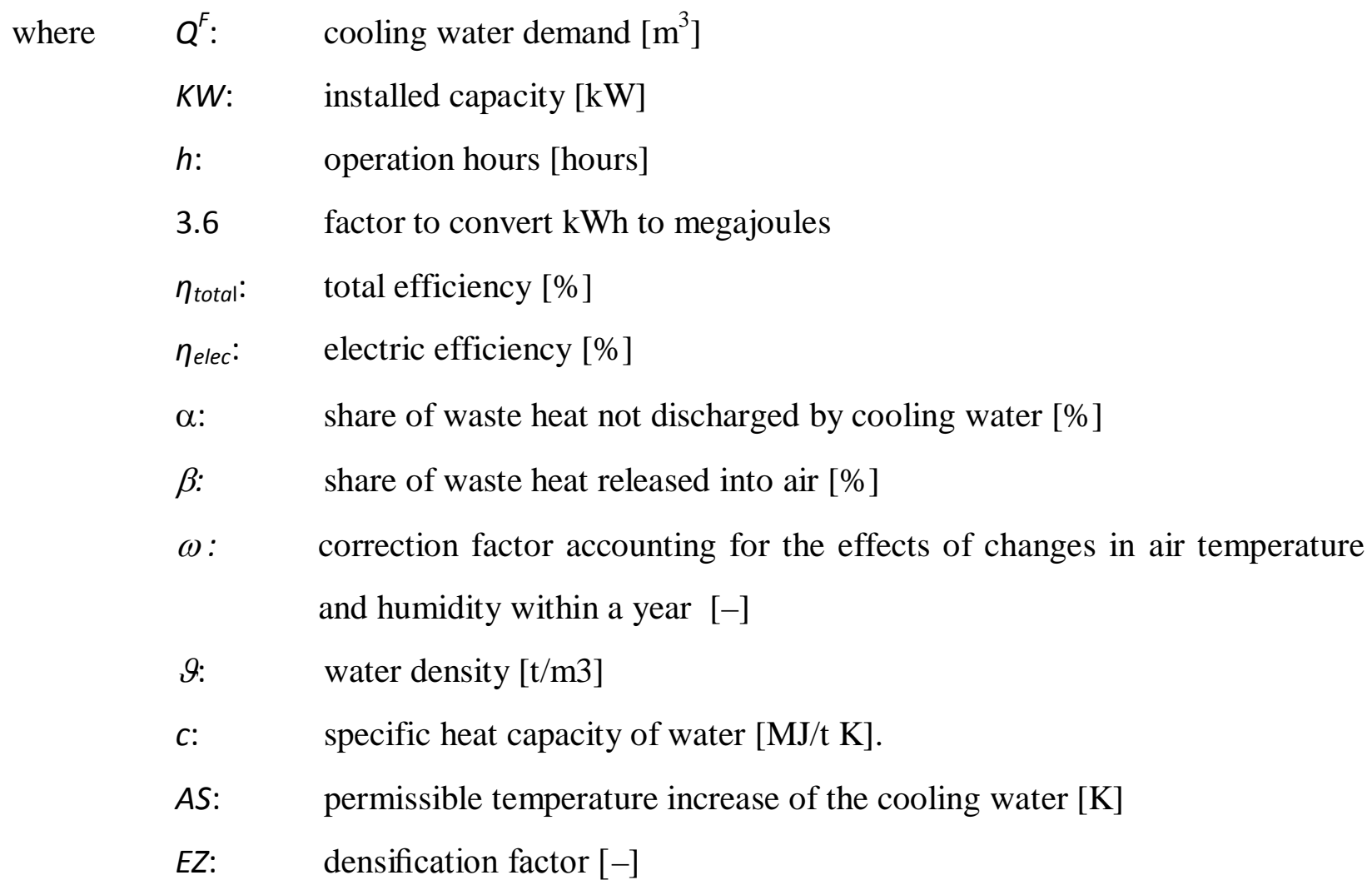

(Koch and Vögele, 2009)

If no cooling tower is used, the waste heat will be released into the receiving surface water. Using a cooling tower, the waste heat will be released mainly into the air. In this case, the demand for cooling water results from losses of water evaporated in the cooling tower. The amount of evaporated water depends on air temperature and humidity as well as on the freshwater which is needed to prevent the build-up of minerals and sediments in the cooling cycle. The impacts of cooling water shortages or limitations on the increase in water temperature can be assessed by transforming equation 1 to

$$
K W=\frac{Q^{F} \cdot \vartheta \cdot c \cdot A S}{h \cdot 3.6 \cdot \frac{1-\eta_{\text {total }}}{\eta_{\text {elec }}} \cdot \lambda \cdot(1-\alpha) \cdot(1-\beta) \cdot \varpi \cdot E Z}
$$

Assuming limitations in the available amount of cooling water $\left(Q_{\max }^{F}\right)$ and a lower permissible temperature increase of the cooling water $\left(A S_{\max }\right)$ the capacity has to reduced to 
$K W_{\max }=\frac{Q_{\max }^{F} \cdot \vartheta \cdot c \cdot A S_{\max }}{h \cdot 3.6 \cdot \frac{1-\eta_{\text {total }}}{\eta_{\text {elec }}} \cdot \lambda \cdot(1-\alpha) \cdot(1-\beta) \cdot \varpi \cdot E Z}$

where

$$
K W_{\text {max }}: \quad \text { usable capacity }[\mathrm{kW}]
$$

Fig. 2 shows the relation between possible electricity production and permissible water intake for a 1200 MW nuclear power plant with a closed-circuit cooling and for a power plant with a once-through cooling system. Usually with higher air temperatures the evaporation and therefore the demand for freshwater increases. If the permissible water intake cannot be extended, the power plant has to reduce its production.

Fig. 2: Permissible water intake and electricity production

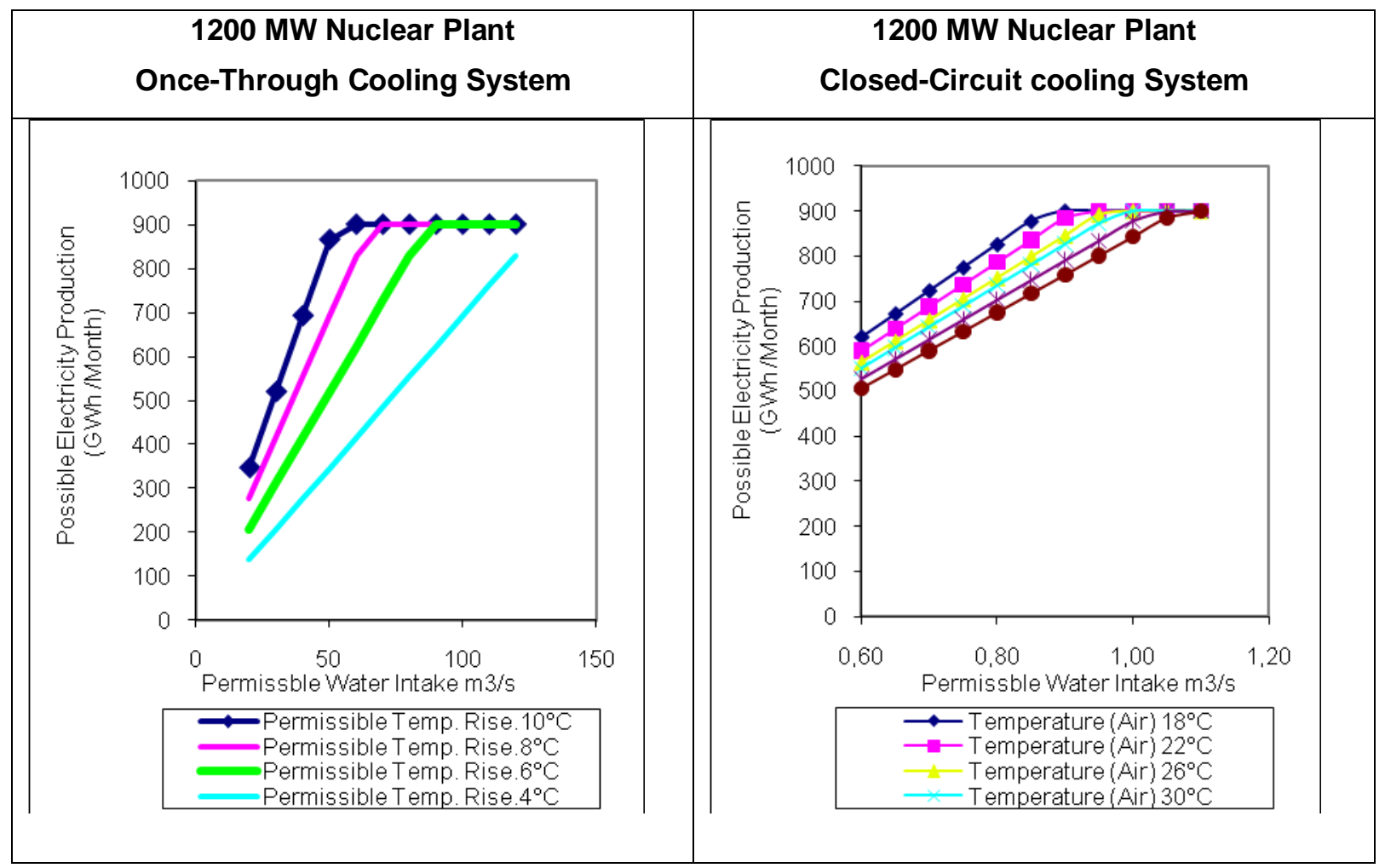


Usually there are several legal constraints for power plants regarding the temperature of the discharged water. So power plant operators are not allowed to discharge water with a temperature above $28 / 30^{\circ} \mathrm{C}$ (once-through cooling system) or $35^{\circ} \mathrm{C}$ (closed-circuit cooling system) and not more than $10^{\circ} \mathrm{C}$ warmer than the water temperature of the river the cooling water is discharged in. A low permissible temperature can be compensated with a higher volume of cooling water. Again, if the amount of permissible water intake is constrained the power plant has to reduce its production.

According to the relevant literature, the interaction between air and water temperature can be described by:

$$
T_{s}=\mu+\frac{\alpha-\mu}{1+e^{\gamma\left(\beta-T_{\alpha}\right)}}
$$

$$
\begin{aligned}
& \text { where } \quad T_{\mathrm{s}} \text { : stream water temperature }\left[{ }^{\circ} \mathrm{C}\right] \\
& T_{\alpha}: \quad \text { air temperature }\left[{ }^{\circ} \mathrm{C}\right] \\
& \mu \text { : estimated minimum stream temperature }\left[{ }^{\circ} \mathrm{C}\right] \\
& \alpha \text { : maximum stream temperature }\left[{ }^{\circ} \mathrm{C}\right] \\
& \gamma: \quad \text { steepest slope of the function }\left[{ }^{\circ}\right] \\
& \beta \text { : } \quad \text { air temperature at the inflection point }\left[{ }^{\circ} \mathrm{C}\right]
\end{aligned}
$$

(Mohseni, Stefan and Erickson 1998).

Besides the analysis of the vulnerability of nuclear power plants to changes in air and water temperatures, we investigate how climate-change induced modifications of the power plant's production affect the European electricity exchange system. Regarding the influence of changes in electricity production on exand imports of electricity we assume that individual countries adjust their electricity exports by the same rate at which their imports have changed.

\section{III.2 Model Specification}

Our example is based on the electricity supply and exchange situation of August 2007 (IAEA 2004; UCTE 2008). Using a climate change scenario of IPCC we analyse what will happen to electricity production and exchange if air temperature changes as expected in this scenario.

In 2007 Germany, France, Great Britain, Spain and Italy had the highest shares of electricity generation in Europe. In Germany, Italy and Great Britain the demand for electricity was higher than the domestic production in the summer months. So they had to import electricity. Most of the electricity that these countries needed was provided by France (see Fig. 3). 
Fig. 3: Net-electricity production and electricity imp-/export in the year 2007

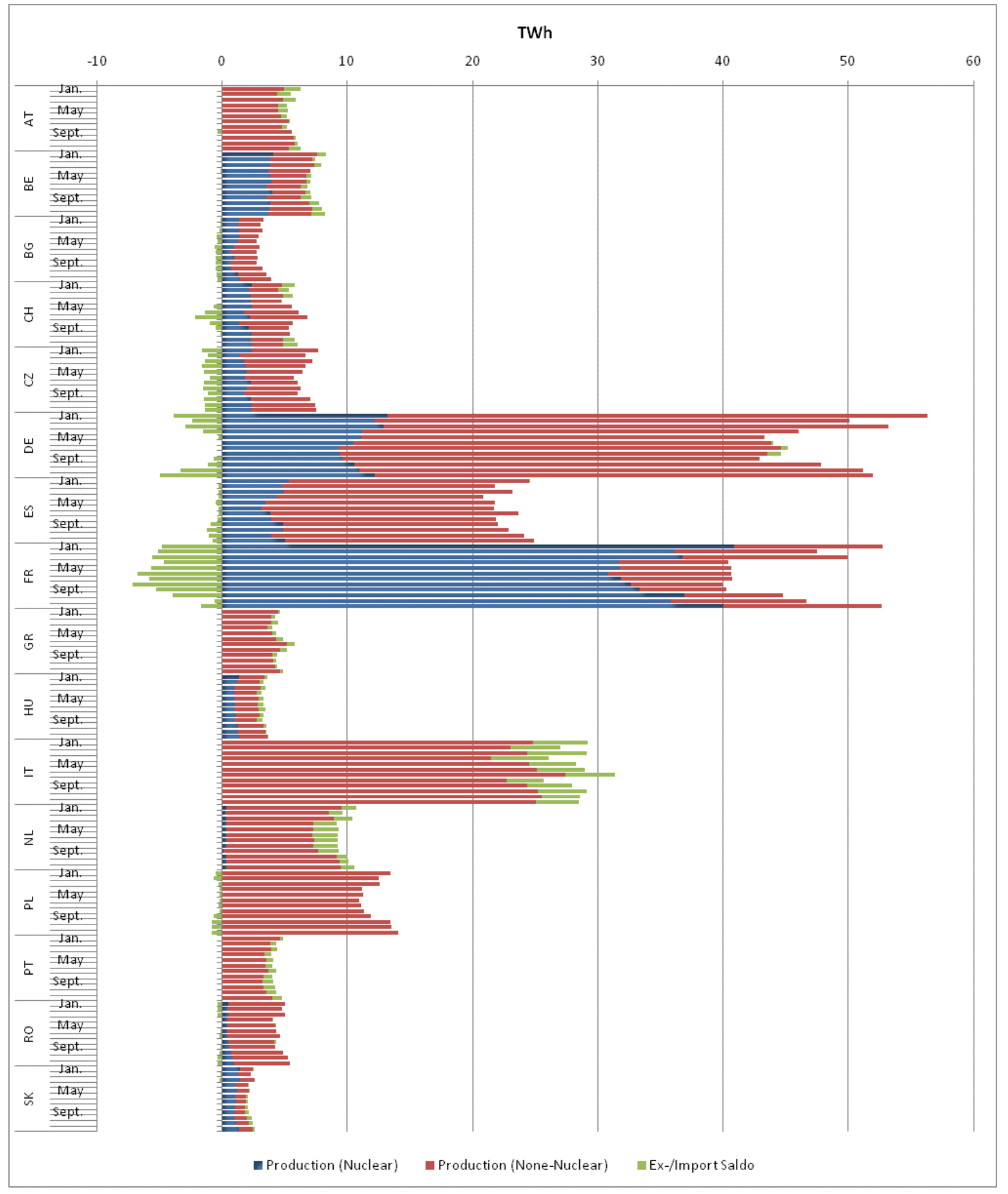

Source: ENTSO-E (2010) 
Usually nuclear power plants are inspected, maintained and refueled each year. If the power plant companies choose July or August to do this, they can avoid cooling problems. According to data of IAEA, we assess the potential to do this for France with $8 \mathrm{GW}$, for Germany with $3.5 \mathrm{GW}$ and 0.5 for Switzerland, Spain, Czech Republic and Hungary (IAEA 2008). Based on data of WORLDCLIM we extracted data for the air temperature of each power plant site and calculated water temperatures.

The climate change scenario corresponds to a projection of the Canadian Centre for Climate Modelling and Analysis (CCCMA) for the "A1" emission storyline of the IPCC. In this storyline a rapid economic development with strong attitudes to market-based solution is assumed. As one result of the increase in $\mathrm{CO}_{2}$ emissions, the air temperature in Europe in the summer will rise by $3^{\circ} \mathrm{K}$ on average (see Govindasamy, Duffy and Coquard 2003; WORLDCLIM 2010).

If the climate changes as Govindasamy, Duffy and Coquard (2003) expect, especially in the south of Europe air and therefore also water temperatures will increase significantly (see Fig. 4). Due to a lack of data and in order to limit the complexity of our study, we have to make several assumptions:

a) In our approach we assume that all nuclear power plants have the same efficiency. In addition, we assume an EZ (densification factor) of 3 for all power plants with closed-circuit cooling system.

b) The demand for reserve capacities and the load still remain on the level of 2007.

c) In the reference situation enough water is available to use the power plants without any constraints. Additionally we assume that at the individual power plant sites the permissible water intake cannot be expanded.

The parameters for the air/water temperature relationship are derived from the literature (Morrill, Bales and Conklin 2005; WWF 2009). Besides air and water temperature data, information on the availability of freshwater is necessary to identify which power plant will get cooling problems if climate changes. Because such data is not available for each of the power plant site we analyse three different scenarios: The first one reflects the situation of August 2007. In the second one (scenario "climate change + slight water scarcity") we assume an increase in air and water temperatures with no extension of the water intake. $^{2}$ In the third scenario (scenario "climate change + more serious water scarcity”) we assume that $10 \%$ less water than in the second scenario will be available.

\footnotetext{
${ }^{2}$ To run the power plants without any limitations on the production on average about $15 \%$ more water will be necessary.
} 
Fig. 4: Air temperature in Europe

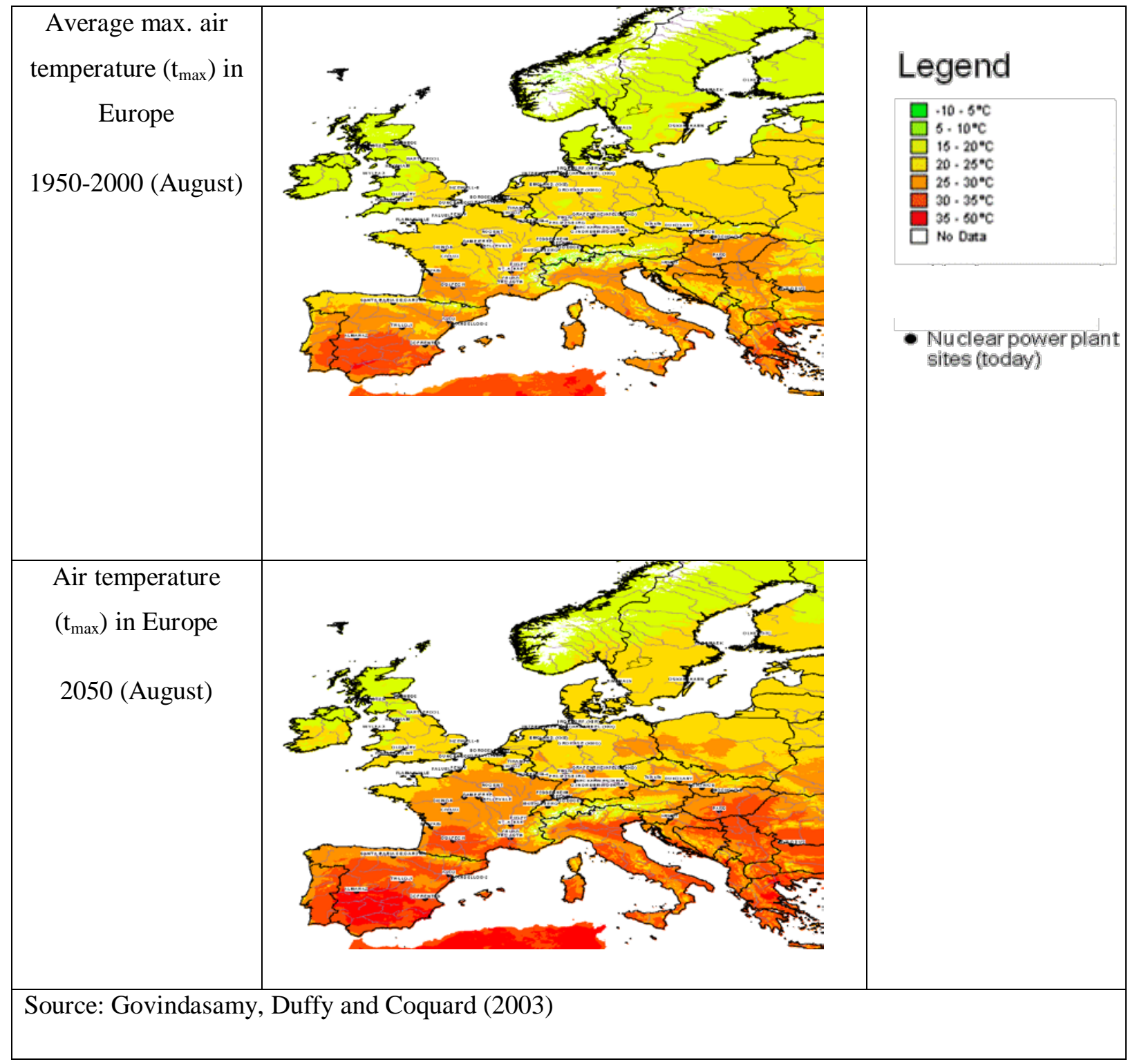

\section{III.3 Results}

The reference situation presented on the top of Fig. 5 reflects the exchanges of power plant capacities in Europe on August, 15th 2007 at 11.00 am according to data published by UCTE (2008). Assuming an increase in air temperatures as Govindasamy, Duffy and Coquard (2003) expect, less power plant capacity will be available in France due to cooling problems. Although the vulnerability to climate change can be reduced by changing the inspection and maintenance periods of critical power plants to summer time France will have to reduce its exports of electricity. In our calculation nuclear power plants in Germany and Switzerland will also face cooling problems. In contrast to France and Spain, these countries are able 
to postpone the inspection and maintenance periods of all critical power plants to August. So the changes in air and water temperatures will have no direct impacts on electricity exports of these countries.

Fig. 5: Load flows (day) on $3^{\text {rd }}$ Wednesday of August at 11:00 a.m. CET in MW

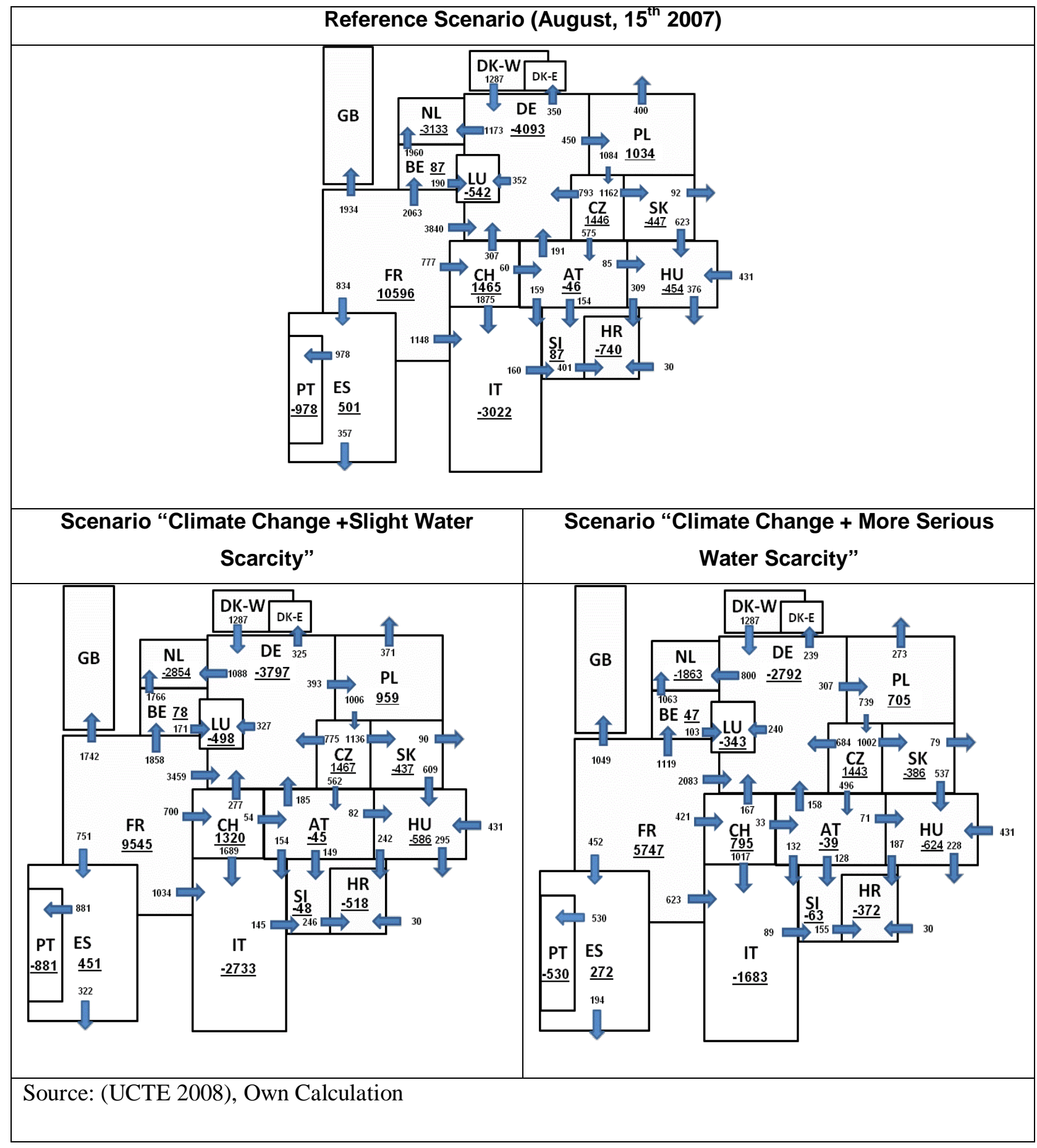


Taking into account that Switzerland as well as Germany and other countries depend more or less on electricity imports from France, these countries will also have to reduce their electricity exports due to the reduction in the imports from France. Thus, in the second scenario, the changes in the electricity exchange system mainly result from constraints of the power plants' output in France and Spain.

The third scenario shows the situation where additional water shortages are taken into account. Besides France and Spain also Switzerland will have to limit nuclear production. All in all, electricity exports will decrease significantly. As the example of the Netherlands shows, not only the direct neighbours of France will have to look for ways to reduce the supply gap but also countries which depend indirectly on electricity from France. Taking electricity import dependency shares into account especially Italy will have problems meeting the demand for electricity if no direct or indirect measures are taken. Other countries will have fewer problems because of their low electricity import share.

\section{Conclusions}

Climate change does not only threaten critical infrastructures directly, but there may also be follow-up effects negatively affecting downstream infrastructures. In our analysis we regarded the follow-up consequences of climate-change induced shortages of water supply for cooling purposes in nuclear power plants. In the future, the threat of water shortages affecting the cooling processes of power plants will become a very important issue. Apart from countries with a high nuclear power production share, countries which depend on electricity imports like the Netherlands will also be affected by climate change.

In order to address the threat of a climate-change induced shortage of electricity supply, there exist two different general strategies or climate policies: "Societies can respond to climate change by adapting to its impacts and by reducing GHG emissions (mitigation), thereby reducing the rate and magnitude of change” (IPCC 2008b: 56). In fact, on the one hand, nuclear power generation is a low carbon option for producing electricity and can hence be seen as a climate change mitigation option if it replaces power generation options using more carbon-intensive fossil fuels like coal or oil. On the other hand, due to the ongoing climate change the European nuclear power sector necessitates adaptation policies. These adaptations have either to be placed in the sector itself or in the upstream water supply sector. Put differently, we may especially distinguish between the following two adaptation categories: 1) improving the management of the upstream critical infrastructure in the shape of water supply (many European river basins are transnational and therefore an international coordination is required in many cases), and 2) improving the management of the downstream critical infrastructure in the shape of electricity generation 
in power plants. Our analysis focused, in turn, mainly on the second category of adaptation options in order to prevent follow-up effects of deteriorations in water supply.

On the one hand, increases in power plant efficiencies as well as replacement of power plants with power plants which do not need a cooling system (e.g., photovoltaic installations) can contribute to reduce the effects of climate change on the electricity supply system. On the other hand, simultaneous changes in the demand for electricity, e.g., due to an increase in the use of air-conditioning, and the concurrent construction of wind-power plants on sites with poor wind conditions in summer will even worsen the situation. Yet, all in all, with coordinated measures of the partners of the European electricity supply system the effects of climate change on the electricity system could be limited. These coordinated measures involve aspects of electricity supply as well as demand and water management to reduce manmade water shortages and the heating up of rivers.

It has also to be taken into account that the considered climate-change induced problems involve international dimensions. A large share of European rivers, and hence water supply from these rivers, are transnational. Thus, improvements of the management of water resources necessitate to a large extent a European coordination in order to be effective. Furthermore, due to the European trade of electricity, deteriorations in the production of electricity will affect a wide range of European countries. Both considered critical infrastructures, water supply and electricity production, therefore, exhibit properties of European critical infrastructures and the European Programme for Critical Infrastructure Protection may provide some assistance to protect them. Yet, overlaps of this programme with other European regulations, e.g., with the EU Water Framework Directive (WFD), should be taken into account and synergies should be exploited. One of the WFD's objectives is to contribute to mitigating the effects of floods and droughts (EC 2000) and consequently the WFD pursues also the protection of critical infrastructures.

Finally, it has to be highlighted that our calculations are based on the assumptions of unchanged load and unchanged use of other power plants. In the past, the plant operators were able to manage disruptions of electricity supply by importing electricity from other countries or using reserve capacities. But even the association of transmission system operators for electricity, Entso-E, finds it hard to provide exact figures for each country on spare capacities ( UCTE, Etso, Nordel, ATSOI, BALSTO and UKTSO 2007). 


\section{References}

BMU (2007): Time to Adapt - Climate Change and the European Water Dimension, Discussion Paper: Electricity.

Bohi, D.R. and Toman, M.A. (1996): The Economics of Energy Security, Kluwer Academic Publishers, Boston/Dordrecht/London.

De Bruijne, M. and van Eeten, M. (2007): Systems that Should Have Failed: Critical Infrastructure Protection in an Institutionally Fragmented Environment, Journal of Contingencies and Crisis Management, Vol. 15, 18-29.

DOE/NETL (2007): Estimating Freshwater Needs to Meet Future Thermoelectric Generation Requirements, Pittsburgh.

EC (2000): Directive 2000/60/EC of the European Parliament and of the Council of 23 October 2000 Establishing a Framework for Community Action in the Field of Water Policy, Official Journal L 327 , 22/12/2000 P. $0001-0073$.

EC (2004): Critical Infrastructure Protection in the Fight against Terrorism, Communication from the Commission to the Council and the European Parliament, COM(2004) 702 final, Brussels.

EC (2005): Green Paper on a European Programme for Critical Infrastructure Protection, COM(2005) 576 final, Brussels.

EC (2006a): A European Strategy for Sustainable, Competitive and Secure Energy, Green Paper, COM(2006) 105 final, Brussels.

EC (2006b): Communication from the Commission on a European Programme for Critical Infrastructure Protection, COM(2006) 786 final, Brussels.

EC (2007): Drought Management Plan Report: Including Agricultural, Drought Indicators and Climate Change Aspects, Water Scarcity and Droughts Expert Network, European Communities, Luxembourg.

EC (2008a): An EU Energy Security and Solidarity Action Plan, Second Strategic Energy Review, COM(2008) 781 final, Brussels.

EC (2008b): Council Directive 2008/114/EC of 8 December 2008 on the Identification and Designation of European Critical Infrastructures and the Assessment of the Need to Improve their Protection, Brussels. 
EC (2008c): European Energy and Transport, DG for Energy and Transport, Luxembourg.

EC (2009a): Adapting to Climate Change: Towards a European Framework for Action, White Paper, COM(2009) 147 final, Brussels.

EC (2009b): Common Implementation Strategy for the Water Framework Directive (2000/60/EC), Guidance Document No. 24, River Basin Management in a Changing Climate, Technical Report - 2009 040.

ENTSO-E (2010): Data Portal CE - Production http://www.entsoe.eu, June 2010.

EPRI (1995): Potential Effects of Climate Change on Electric Utilities. Palo Alto, Electric Power Research Institute.

EUREAU (2009): EUREAU Statistics Overview on Water and Wastewater in Europe 2008, Brussels.

EUROSTAT (2010): Electricity Statistics - Provisional Data for 2009. http://epp.eurostat.ec.europa.eu/portal/page/portal/product details/publication?p_product code=KS-QA$\underline{10-014 .}$

Förster, H. and Lilliestam, J. (2010): Modeling Thermoelectric Power Generation in View of Climate Change, Regional Environmental Change, Online First.

Fritzon, Å.; Ljungkvist, K.; Boin, A. and Rhinard, M. (2007): Protecting Europe’s Critical Infrastructures: Problems and Prospects, Journal of Contingencies and Crisis Management, Vol. 15, 30-41.

Govindasamy, B.; Duffy, P.B. and Coquard, J. (2003): High-resolution Simulations of Global Climate, Part 2: Effects of Increased Greenhouse Cases. Climate Dynamics, 21, 391-404.

Hurd, B. and Harrod, M. (2001): Water Resources: Economic Analysis. In: Mendelsohn, R. (ed.) Global Warming and the American Economy. Cheltenham, Edward Elgar Publishing Ltd.

IAEA (2004): Operating Experience with Nuclear Power Stations in Member States in 2003, Vienna.

IAEA (2008): Operating Experience with Nuclear Power Stations in Member States in 2007, Vienna.

IEA (2007): Energy Security and Climate Policy - Assessing Interactions, OECD/IEA, Paris.

IPCC (2008a): Climate Change 2007: Impacts, Adaptation and Vulnerability, Cambridge University Press, Cambridge.

IPCC (2008b): Climate Change 2007: Synthesis Report, Cambridge University Press, Cambridge. 
IRGC (2009): Risk Governance Deficits: An Analysis and Illustration of the Most Common Deficits in Risk Governance, Report, Geneva.

Koch, H. and Vögele, S. (2009): Dynamic Modelling of Water Demand, Water Availability and Adaptation Strategies for Power Plants to Global Change, Ecological Economics, Vol. 68, 2031-2039.

Kröger, W. (2008): Critical Infrastructures at Risk: A Need for a New Conceptual Approach and Extended Analytical Tools, Reliability Engineering and System Safety, Vol. 93, 1781-1787.

Lindström, M. (2009): The European Programme for Critical Infrastructure Protection, Chapter 3, in: Crisis Management in the European Union, edited by S. Olsson, Springer-Verlag, Berlin, Heidelberg.

Little, R.G. (2002): Controlling Cascading Failure: Understanding the Vulnerabilities of Interconnected Infrastructures, Journal of Urban Technology, Vol. 9, 109-123.

Löschel, A.; Moslener, U. and Rübbelke, D.T.G. (2010): Indicatos of Energy Security in Industrialised Countries, Energy Policy, Vol. 38, 1665-1671.

Mohseni, O.; Stefan, H.G. and Erickson, T.R. (1998): A Nonlinear Regression Model for Weekly Stream Temperatures, Water Resources Research, Vol. 34, 2685-2692.

Morrill, J. C.; Bales, R.C. and Conklin, M.H. (2005): Estimating Stream Temperature from Air Temperature: Implications for Future Water Quality, Journal of Environmental Engineering, Vol. 131, 139-146.

Müller, U.; Greis, S. and Rothstein, B. (2007): Impacts on Water Temperatures of Selected German Rivers and on Electricity Production of Thermal Power Plants due to Climate Change. 8. Forum DKKV/CEDIM: Disaster Reduction in Climate Change, Karlsruhe.

OECD (2003): Emerging Risks in the $21^{\text {st }}$ Century: An Agenda for Action, Paris.

Pulido-Velazquez, M.; Andreu, J.; Sahuquillo, A. and Pulido-Velazquez, D. (2008): Hydro-Economic River Basin Modelling: The Application of a Holistic Surface-Groundwater Model to Assess Opportunity Costs of Water Use in Spain, Ecological Economics, Vol. 66, 51-65.

Pursiainen, C. (2009): The Challenges for European Critical Infrastructure Protection, Journal of European Integration, Vol. 31, 721-739.

Showers, K.B. (2002): Water Scarcity and Urban Africa: An Overview of Urban-Rural Water Linkages, World Development, Vol. 30, 621-648. 
Svendsen, N.K. and Wolthusen, S.D. (2007): Connectivity Models of Interdependency in Mixed-type Critical Infrastructure Networks, Information Technology Technical Report, Vol. 12, 44-55.

UCTE (2004): August 2003 - Monthly Provisional Values, Brussels.

UCTE (2008): August 2007 - Monthly Provisional Values, Brussels.

UCTE, Etso, Nordel, ATSOI, BALSTO and UKTSO (2007): Winter Outlook Report 2007-2008. http://www.entsoe.eu/fileadmin/user_upload/_library/publications/ce/otherreports/Winter_Outlook_Repor t 2007-2008.pdf, June 2010.

Watts, D. (2003): Security \& Vulnerability in Electric Power Systems, NAPS 2003, $35^{\text {th }}$ North American Power Symposium, University of Missouri-Rolla in Rolla, Missouri, 559-566.

WORLDCLIM (2010): Global Climate Data. http://www.worldclim.org, June 2010.

WWF (2009): Die mögliche Wirkung des Klimawandels auf Wassertemperaturen von Fliessgewässern, Frankfurt am Main.

Zebisch, M.; Grothmann, T.M.; Schröter, D.; Hasse, C.; Fritsch, U. and Cramer, W. (2005): Climate Change in Germany: Vulnerability and Adaptation of Climate-sensitive Sectors. Federal Environmental Agency, Climate Change 10/05, Dessau. 


\title{
BC3 WORKING PAPER SERIES
}

\author{
Basque Centre for Climate Change (BC3), Bilbao, Spain
}

The BC3 Working Paper Series is available on the internet at the following addresses:

http://www.bc3research.org/lits_publications.html

http://ideas.repec.org/s/bcc/wpaper.html

BC3 Working Papers available (see website for full list):

2009-05

M.C. Gallastegui and Ibon Galarraga: Climate Change and Knowledge Communities

2009-06

Ramon Arigoni Ortiz and Anil Markandya: Literature Review of Integrated Impact Assessment Models of Climate Change with Emphasis on Damage Functions

Agustin del Prado, Anita Shepherd, Lianhai Wu, Cairistiona Topp, Dominic Moran, Bert Tolkamp and David Chadwick: Modelling the Effect of Climate Change on Environmental Pollution Losses from Dairy Systems in the UK

Ibon Galarraga and Anil Markandya: Climate Change and Its Socioeconomic Importance

Julia Martin-Ortega and Anil Markandya: The Costs of Drought: the Exceptional 2007-2008 Case of Barcelona

Elena Ojea, Ranjan Ghosh, Bharat B. Agrawal and P. K. Joshi: The Costs of Ecosystem Adaptation: Methodology and Estimates for Indian Forests

Luis M. Abadie, José M. Chamorro, Mikel Gonzáez-Eguino: Optimal Investment in Energy Efficiency under Uncertainty

Sara L. M. Trærup, Ramon Arigoni Ortiz and Anil Markandya: The Health Impacts of Climate Change: A Study of Cholera in Tanzania

Mikel González-Eguino, Ibon Galarraga and Alberto Ansuategi: Carbon leakage and the Future of Old Industrial Regions after Copenhagen

Roger Fouquet: Divergences in the Long Run Trends in the Price of Energy and of Energy Services

Giacomo Giannoccaro and Julia Martin-Ortega: Environmental Concerns in Water Pricing Policy: an Application of Data Envelopment Analysis (DEA)

Roger Fouquet: The Slow Search for Solutions: Lessons from Historical Energy Transitions by Sector and Service

Ibon Galarraga, Mikel González-Eguino and Anil Markandya: Evaluating the Role of Energy Efficiency Labels: the Case of Dish Washers

Luis M. Abadie, Mikel González-Eguino and José M. Chamorro: Optimal Abandonment of Coal-Fired Stations in the EU

2010-08

Dirk Rübbelke and Stefan Vögele: Impacts of Climate Change on European Critical Infrastructures: The Case of the Power Sector 